\title{
Ketamine and MAG Lipase Inhibitor-Dependent Reversal of Evolving Depressive-Like Behavior During Forced Abstinence From Alcohol Drinking
}

\author{
Katherine M Holleran 1,2,3,4, Hadley H Wilson'2, Tracy L Fetterly 1,2,3,4, Rebecca J Bluett', \\ Samuel W Centanni ${ }^{1,3}$, Rachel A Gilfarb ${ }^{2}$, Lauren ER Rocco ${ }^{2}$, Sachin Patel ${ }^{1,2,3,4}$ and Danny G Winder, ${ }^{*, 2,3,4}$ \\ 'Department of Molecular Physiology and Biophysics, Vanderbilt University, Nashville, TN, USA; ${ }^{2}$ Vanderbilt Brain Institute, Vanderbilt University, \\ Nashville, TN, USA; ${ }^{3}$ Neuroscience Program in Substance Abuse, Vanderbilt University, Nashville, TN, USA; ${ }^{4}$ Kennedy Center, Vanderbilt University, \\ Nashville, TN, USA
}

\begin{abstract}
Although alcoholism and depression are highly comorbid, treatment options that take this into account are lacking, and mouse models of alcohol (ethanol $(\mathrm{EtOH})$ ) intake-induced depressive-like behavior have not been well established. Recent studies utilizing contingent EtOH administration through prolonged two-bottle choice access have demonstrated depression-like behavior following EtOH abstinence in singly housed female C57BL/6] mice. In the present study, we found that depression-like behavior in the forced swim test (FST) is revealed only after a protracted (2 weeks), but not acute ( $24 \mathrm{~h}$ ), abstinence period. No effect on anxiety-like behavior in the EPM was observed. Further, we found that, once established, the affective disturbance is long-lasting, as we observed significantly enhanced latencies to approach food even 35 days after ethanol withdrawal in the novelty-suppressed feeding test (NSFT). We were able to reverse affective disturbances measured in the NSFT following EtOH abstinence utilizing the N-methyl D-aspartate receptor (NMDAR) antagonist and antidepressant ketamine but not memantine, another NMDAR antagonist. Pretreatment with the monoacylglycerol (MAG) lipase inhibitor JZ- I 84 also reduced affective disturbances in the NSFT in ethanol withdrawn mice, and this effect was prevented by co-administration of the $\mathrm{CBI}$ inverse agonist rimonabant. Endocannabinoid levels were decreased within the BLA during abstinence compared with during drinking. Finally, we demonstrate that the depressive behaviors observed do not require a sucrose fade and that this drinking paradigm may favor the development of habit-like EtOH consumption. These data could set the stage for developing novel treatment approaches for alcohol-withdrawal-induced mood and anxiety disorders.
\end{abstract}

Neuropsychopharmacology (20 I6) 4I, 2062-207I; doi:I 0.I038/npp.20 I6.3; published online I0 February 2016

\section{INTRODUCTION}

Alcohol use disorders (AUDs) are strongly comorbid with depression (Grant et al, 2015), and alcohol withdrawal is associated with affective disturbances (Heilig et al, 2010). Developing an understanding of AUD-depression interactions, as well as treatments for these comorbid conditions, represents a clinically crucial research area.

Rodent models of alcohol (ethanol (EtOH)) administration, typically non-contingent, have largely focused on anxiety-like behavior during early withdrawal (Kash et al, 2009; Kliethermes, 2005). These and other negative affective behaviors have proven difficult to reliably induce in C57BL/6J mice (Daut et al, 2015) frequently utilized in

\footnotetext{
*Correspondence: Dr DG Winder, Department of Molecular Physiology and Biophysics, Vanderbilt Brain Institute, Neuroscience Program in Substance Abuse, Kennedy Center, Vanderbilt University, Nashville, TN 37221, USA, Tel: + I 615322 II44, Fax: + I 615322 1462, E-mail: Danny.Winder@Vanderbilt.edu

Received 14 August 2015; revised 4 January 2016; accepted 5 January 2016; accepted article preview online II January 2016
}

drinking studies (Kash et al, 2009; Lovinger and Crabbe, 2005). Recent studies in C57BL/6J mice have modeled depression-like behavior following abstinence from contingent EtOH administration (Lee et al, 2015; Pang et al, 2013; Stevenson et al, 2009). Two weeks of abstinence from EtOH induced a pattern of behavior consistent with onset of a depressive phenotype. This included disruptions in affective measures in the forced swim test (FST), saccharin preference test, and novelty-suppressed feeding test (NSFT) but not in the elevated plus maze (EPM) or light-dark box (Pang et al, 2013).

Here we replicated and extended the findings of Pang et al (2013). We elucidated a timeline by examining behavior 1 , 15-18, and 35 days after EtOH removal. Treatments with typical antidepressants (selective serotonin reuptake inhibitors (SSRIs)) are notoriously troublesome owing to low treatment efficacy and long lag time (weeks to months) before benefits manifest (Gartlehner et al, 2012), and such antidepressants can escalate $\mathrm{EtOH}$ consumption in rats (Alen et al, 2013). We examined alternative pharmacological treatments in reversing depression-like behavior in mice. The $N$-methyl D-aspartate receptor (NMDAR) antagonist 
a
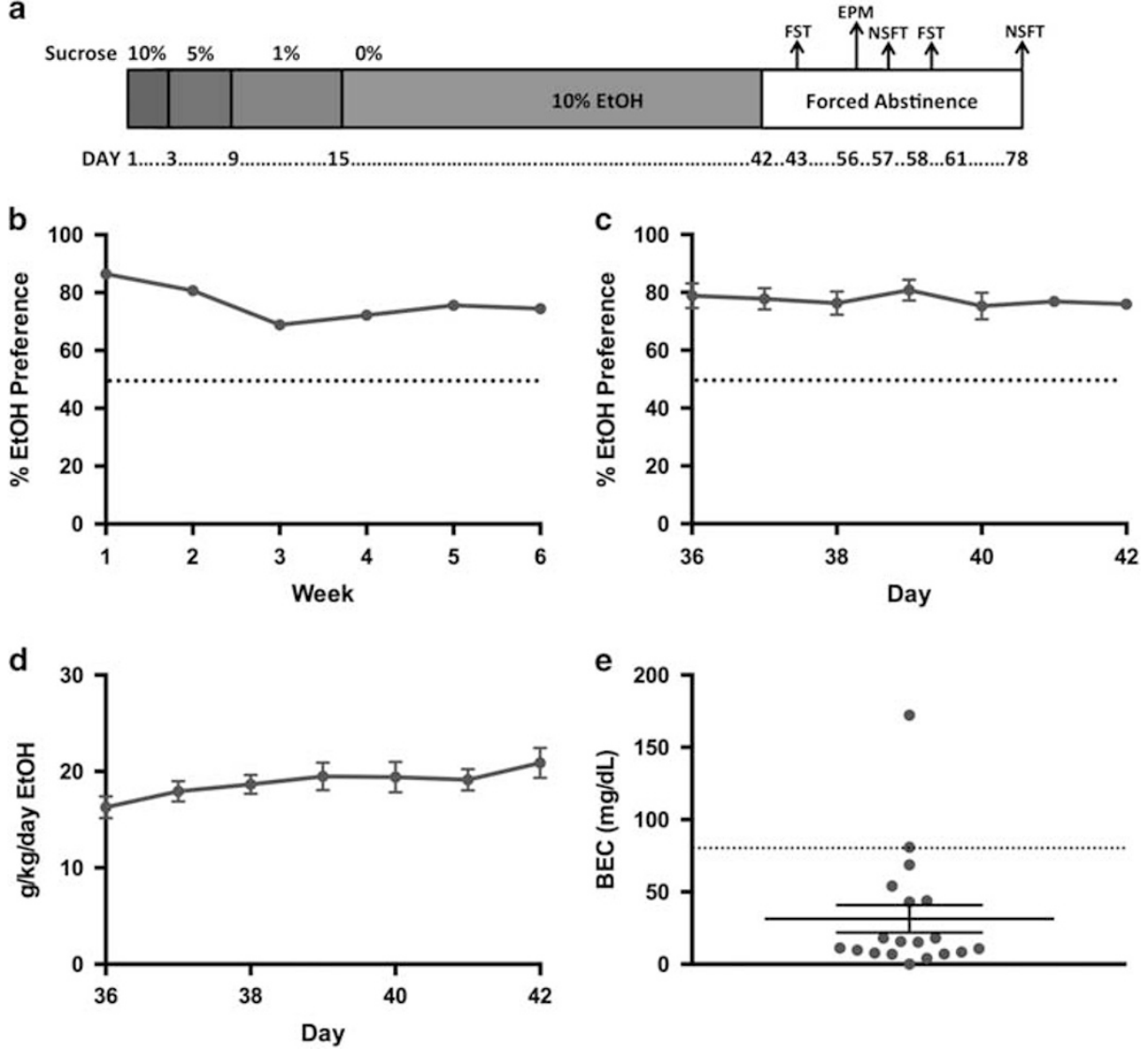

Figure I EtOH two-bottle choice with sucrose fade reliably induces significant EtOH preference. (a) Timeline of EtOH two-bottle choice with sucrose fade. $10 \% \mathrm{EtOH}$ given from day I to day 42 with sucrose fade as indicated. (b) Preference for EtOH-containing sipper during 6-week access to EtOH $(\mathrm{N}=85)$. (c) Daily preference for EtOH-containing sipper during the last week of access in the first cohort $(\mathrm{N}=12$ ). (d) Daily EtOH consumption (g/kg/day) during the last week of access in the first cohort $(N=12)$. (e) Individual BECs for mice after 42 days of drinking. Data are represented as mean \pm SEM. Dashed line indicates $50 \%$ preference in panels (b) and (c); dashed line indicates $80 \mathrm{mg} / \mathrm{dl}$ in panel (e). EPM, elevated plus maze; FST, forced swim test; NSFT, novelty-suppressed feeding test.

ketamine has been extensively studied for antidepressant efficacy in humans (Berman et al, 2000) and rodents (Autry et al, 2011; Li et al, 2011). Here we examined the ability of NMDAR antagonists ketamine and memantine to reduce depressive behavior following 2 weeks of $\mathrm{EtOH}$ abstinence. We also examined the role of endocannabinoids (eCBs) in this phenotype, as stress-induced affective behaviors can be ameliorated by increasing eCB levels (Sumislawski et al, 2011). We tested the monoacylglycerol (MAG) lipase inhibitor JZL-184 in reversing disrupted affective behavior following $\mathrm{EtOH}$ abstinence and whether this effect was blocked by the $\mathrm{CB} 1$ receptor inverse agonist rimonabant. Further, we examined eCB levels in discrete brain regions during EtOH exposure vs abstinence. Finally, we examined whether motivation for EtOH drinking becomes more habit-like following this paradigm.

\section{MATERIALS AND METHODS}

Detailed methods are provided in Supplementary Information.

\section{Animals}

Two hundred and thirty-two female C57BL/6J mice (Jackson Laboratories; Bar Harbor, ME) were used for this study.
Females were chosen for two reasons. In humans, females are disproportionately affected by major depressive disorder (MDD; Grigoriadis and Robinson, 2007). Additionally, female C57BL/6J mice develop higher preference for $10 \%$ EtOH over water (Middaugh et al, 1999). Thus we chose a population that may prove more susceptible to affective disturbances and elevated EtOH preference. Mice were delivered at 7 weeks of age and then singly housed and maintained on $12 \mathrm{~h} \mathrm{light/dark} \mathrm{cycle} \mathrm{(lights} \mathrm{on} \mathrm{at} 0600$ hours) under controlled temperature $\left(20-25^{\circ} \mathrm{C}\right)$ and humidity (30-50\%) levels. Treatments were approved by the Vanderbilt Animal Care and Use Committee.

\section{Two-Bottle Choice EtOH Drinking}

Mice had access to two sippers throughout the experiment. Mice in the control groups $(N=69)$ received water in both sippers. In EtOH drinking mice $(N=163)$, either sucrose fade $(N=85$; Figure 1a) or EtOH $\operatorname{ramp}(N=78$; Figure $5 \mathrm{a})$ was used. EtOH was provided during the first 6 weeks. After this, blood and tissue was collected for blood $\mathrm{EtOH}$ concentration (BEC; $N=19$ ) and eCB analysis, respectively, described below. In other mice, following EtOH access, 10\% $\mathrm{EtOH}$ was replaced with either water for abstinence-related 
behavioral studies $(N=144)$ or $3 \% \mathrm{EtOH}$ for the habit-like drinking study $(N=10)$.

\section{BEC Analysis}

BECs were obtained from blood serum samples of mice on day 42 of EtOH access using a colorometric assay as previously described (Prencipe et al, 1987).

\section{Forced Swim Test}

Following $1 \mathrm{~h}$ acclimation to the testing room, mice were exposed to a 6-min forced swim in a cylinder filled with water $\left(23-25^{\circ} \mathrm{C}\right)$ such that mice could not touch the bottom. Time immobile (no movement except those required to remain afloat) was scored by a blinded observer via video recording during the last $4 \mathrm{~min}$ of swim.

\section{Elevated Plus Maze}

As described previously (Kash et al, 2009), mice were tested for time spent on open and closed arms over $5 \mathrm{~min}$.

\section{Novelty-Suppressed Feeding Test}

As previously described (Pang et al, 2013) food-deprived mice were tested for latency to first bite of food in a novel arena.

\section{Mass Spectrometry to Determine eCB Metabolites}

Tissue punches were obtained from mice either after 42 days of continuous access to EtOH or after 15 days of withdrawal. Samples were then analyzed via mass spectrometry for levels of 2-AG, arachidonic acid (AA), and anandamide (AEA).

\section{Statistics}

All data are represented as mean \pm SEM. All statistics were run using Prism 6 (Graphpad, La Jolla, CA). BECs were determined by interpolation of concentrations utilizing absorbance values of known EtOH standards. Differences between groups were assessed using $t$-tests, one-way ANOVAs, and two-way ANOVAs, with significance set at $\alpha=0.05$. When significant main effects were obtained using ANOVA tests, appropriate post-hoc comparisons between groups were performed.

\section{RESULTS}

\section{EtOH Two-Bottle Choice Produces Significant EtOH Preference in Singly Housed Female Mice}

Female C57Bl/6J mice were given $24 \mathrm{~h}$ access to both $10 \%$ $\mathrm{EtOH}$ and water for 6 weeks (Figure 1a). Mice preferred $10 \% \mathrm{EtOH}$ over water (Figure $1 \mathrm{~b} ; P<0.0001$ for each time point; overall preference $=76.39 \pm 0.606 \%$ ), as previously reported (Pang et al, 2013). During the last week, preference (Figure $1 \mathrm{c}$ ) and $\mathrm{g} / \mathrm{kg} /$ day (Figure $1 \mathrm{~d}$ ) were relatively stable. BECs were sampled on day 42 of $\mathrm{EtOH}$ access $(31.37 \pm 9.47 \mathrm{mg} / \mathrm{dl}$; range $0-172.3 \mathrm{mg} / \mathrm{dl}$; Figures $1 \mathrm{e}$ and $5 a)$. Animal weights did not differ between groups $(P>0.05$; results not shown).

\section{Depression-Like Behavior Requires Protracted Forced Abstinence}

The FST and NSFT were utilized to measure affective behavior. FST immobility is a well-known proxy for depression-like behavior. Increased NSFT latency is typically attributed to anxiety-like behavior (Bodnoff et al, 1988; Dulawa et al, 2004). However, other studies have implicated alterations in NSFT latency as indicative of depression-like behavior (Li et al, 2011; Pang et al, 2013; Santarelli et al, 2003). Additionally, in the NSFT, chronic treatment with SSRIs is required to reduce latencies to consume, similar to human depression treatment (Bodnoff et al, 1988; Dulawa and Hen, 2005; Santarelli et al, 2003). As demonstrated previously (Pang et al, 2013), we observed increased FST immobility in $\mathrm{EtOH}$ mice following 18 days of forced abstinence (Figure 2a; $P<0.001, N=10-12$ /group). However, in another cohort, we found no significant difference in FST immobility between EtOH and control mice $24 \mathrm{~h}$ following $\mathrm{EtOH}$ removal (Figure 2b; $P=0.909, N=13-14$ / group), suggesting that depression-like behavior in this paradigm requires protracted abstinence.

\section{Forced Abstinence from EtOH does not Affect EPM Behavior}

Anxiety-like behavior occurs in C57BL/6J mice following early withdrawal from intermittent vaporized $\mathrm{EtOH}$ (Kash et al, 2009; Kliethermes, 2005) but not at later time points (Daut et al, 2015; Pang et al, 2013). We examined whether forced abstinence from $\mathrm{EtOH}$ drinking in this paradigm would alter anxiety-like behavior measured by the EPM and found no effect on open arm time (Figure 2c; $P=0.738, N=11 /$ group) or distance traveled (Figure 2c'; $P=0.835)$ after 14 days of EtOH forced abstinence.

\section{Forced Abstinence from EtOH Produces Long-Lasting Disruption of Affective Behavior in the NSFT}

We aimed to replicate earlier findings on ethanol abstinence actions on NSFT behavior (Pang et al, 2013) as well as examine persistence of these alterations. Mice were tested at 15 and 35 days following EtOH removal (Figure 2d). A twoway repeated-measures ANOVA revealed main effects for time $(\mathrm{F}(1,31)=9.769, P=0.004)$, treatment $(\mathrm{F}(1,31)=21.40$, $P<0.0001)$, and matching subjects $(\mathrm{F}(1,31)=2.037$, $P=0.026)$ but no interaction $(\mathrm{F}(1,31)=0.2576, P=0.6153)$. Post-hoc analysis using Sidak's multiple comparisons tests revealed that EtOH-exposed mice had higher latencies at both $15(P<0.001)$ and 35 days $(P<0.01)$ compared with controls, indicating a persistent affective phenotype in the NSFT following EtOH forced abstinence.

\section{Increased Latency in NSFT Following EtOH Forced Abstinence is Ameliorated by Ketamine and JZL-184 but not by Memantine}

Ketamine has rapid and long-lasting antidepressant effects in humans (Berman et al, 2000; Zarate et al, 2006a,b) and rodents (Louderback et al, 2013; Li et al, 2011; Autry et al, 2011). We postulated that ketamine would ameliorate affective disturbances induced by $\mathrm{EtOH}$ abstinence. EtOH 



Figure 2 Removal of EtOH induces long-lasting depression-like behavior that requires an abstinence period. (a, b) Abstinence from EtOH significantly increases immobility time in the FST (a) I 8 days, but not (b) I day, after EtOH removal. (c) Anxiety-like behavior in the EPM is unaffected I 4 days after EtOH abstinence as measured by time spent in the open or closed arms of the apparatus. (c') Locomotion, measured by distance traveled in the EPM apparatus, is unaltered after 14 days of EtOH abstinence. (d) Depression-like behavior induced by EtOH abstinence is long-lasting. EtOH-exposed mice demonstrate depression-like behavior - increased latency to consume chow in the NSFT_at both 15 and 35 days following removal of EtOH. Data are represented as mean \pm SEM. $* * * P<0.01 ; * * * * P<0.001$.

and control mice were treated with saline or ketamine $(3 \mathrm{mg} / \mathrm{kg}$ in saline; $N=6-7 /$ group) $30 \mathrm{~min}$ before the NSFT (Figure 3). We chose a dose that reduces depression-like behavior in rodents at this time point (Autry et al, 2011; Louderback et al, 2013). Two-way ANOVA revealed main effects of EtOH exposure $(\mathrm{F}(1,23)=9.649, \quad P=0.005)$ and drug $(\mathrm{F}(1,23)=10.66, P=0.003)$ but no interaction $(\mathrm{F}(1,23)=3.633$, $P=0.069)$. Post-hoc analysis using Fisher's LSD revealed that only $\mathrm{EtOH}+\mathrm{Sal}$ mice significantly differed from Contr+Sal $(P=0.001)$ and that ketamine+EtOH mice were indistinguishable from Contr+Sal mice $(P>0.05)$. Thus ketamine reversed affective disturbances in EtOH-exposed mice to baseline levels.

Because EtOH and ketamine both inhibit NMDARs, we wondered whether ketamine was eliciting antidepressant-like effects in this model by mimicking EtOH. To test this, we utilized memantine-another NMDAR antagonist. This drug interested us because it has not been shown to reduce depression in either humans (Zarate et al, 2006b) or rodents (Gideons et al, 2014). We administered memantine $(20 \mathrm{mg} / \mathrm{kg}$ in saline; $N=11-12 /$ group $)$ in control and EtOH mice 30 min before the NSFT (Figure 4a) after 15 days of abstinence (main statistics below). We chose this dosage used in a previous study examining memantine for antidepressant efficacy (Gideons et al, 2014). Post-hoc analysis with Fisher's LSD showed that latencies for both the $\mathrm{EtOH}+\mathrm{DMSO}$ and $\mathrm{EtOH}+\mathrm{Mem}$ groups were significantly higher than the Control+DMSO group $(P<0.05$ for both groups), indicating that memantine did not reduce affective disturbances.

The eCB system has been implicated in depressionand anxiety-like behavior (Fowler, 2015; Morena et al, 2015). Increasing 2-AG levels through MAG lipase inhibition by JZL-184 reduces stress-induced anxiety-like behavior 


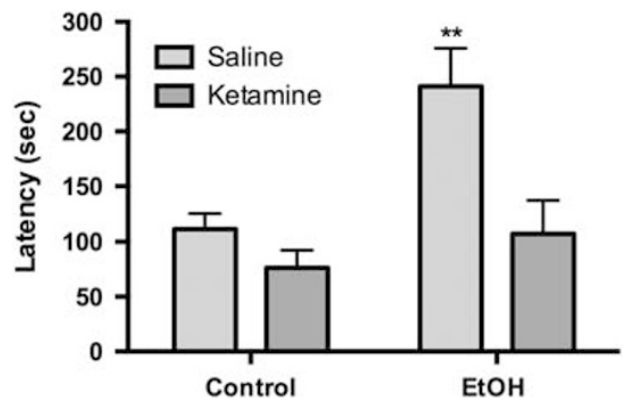

Figure 3 Ketamine ( $3 \mathrm{mg} / \mathrm{kg}$; 30 min prior to testing) was able to reduce NSFT latency to control levels in $\mathrm{EtOH}$ mice 15 days after $\mathrm{EtOH}$ removal. Groups were compared with Control-Vehicle for statistics. Data represented as mean \pm SEM. ${ }^{*} * P<0.01$

(Sumislawski et al, 2011). Additionally, ethanol is not able to substitute for cannabinoids in discrimination tasks in rodents (Jarbe et al, 2010; McMahon et al, 2008). We administered JZL-184 (8 mg/kg in DMSO; $N=7-8 /$ group $)$ or vehicle (DMSO; $N=7-8$ /group) in control and $\mathrm{EtOH}$ mice 15 days after EtOH removal (Figure 4a). Two hours later, mice were tested in the NSFT. Two-way ANOVA revealed a main effect of EtOH $(\mathrm{F}(1,45)=10.51$, $P=0.002)$ but no main effect of drug $(\mathrm{F}(2,45)=1.531$, $P=0.227) \quad$ or interaction $\quad(\mathrm{F}(2,45)=2.140, \quad P=0.130)$. Post-hoc analysis with Fisher's LSD showed that EtOH+ JZL-184 mice were not significantly different from the Control+DMSO group $(P>0.05)$. Similar to ketamine, JZL-184 reversed affective disturbances induced by EtOH abstinence.

To demonstrate that the effect of JZL-184 was mediated by the CB1 receptor, we co-administered JZL-184 with the CB1 inverse agonist rimonabant $(1 \mathrm{mg} / \mathrm{kg}$ in $\mathrm{DMSO}$, i.p.) $v s$ JZL-184 alone $(8 \mathrm{mg} / \mathrm{kg}$ in DMSO, i.p.) or vehicle $(N=9-10 /$ group) in control and $\mathrm{EtOH}$ mice 15 days after $\mathrm{EtOH}$ removal (Figure 4b). Two hours following injection, mice were tested in the NSFT. This rimonabant dosage does not alter affective behavior in a similar task when administered alone (Gamble-George et al, 2013). One-way ANOVA revealed a significant effect of treatment $(\mathrm{F}(3,34)=6.578$; $P=0.0013)$. Fisher's LSD post-hoc test revealed significant differences between control-vehicle mice and EtOH-vehicle $(P<0.05)$ and EtOH-JZL+Rim $(P<0.001)$ mice, between EtOH-vehicle and EtOH-JZL $(P<0.05)$ mice, and between EtOH-JZL and EtOH-JZL+Rim $(P<0.01)$ mice. No differences were found between control-vehicle and EtOH-JZL $(P>0.05)$ mice or between EtOH-vehicle and EtOH-JZL+Rim $(P>0.05)$ mice. Thus rimonabant prevented the alleviating effect of JZL-184.

\section{eCB Levels Differ Between EtOH Access and EtOH Abstinence}

Given the robust modulation of abstinence-induced affective disturbances through eCB manipulation, we postulated that discrete brain regions may display altered levels of eCBs during drinking $v s$ abstinence. Mass spectrometry was used to examine the levels of 2-AG, AEA, and AA in tissue punches from coronal brain sections taken from basolateral
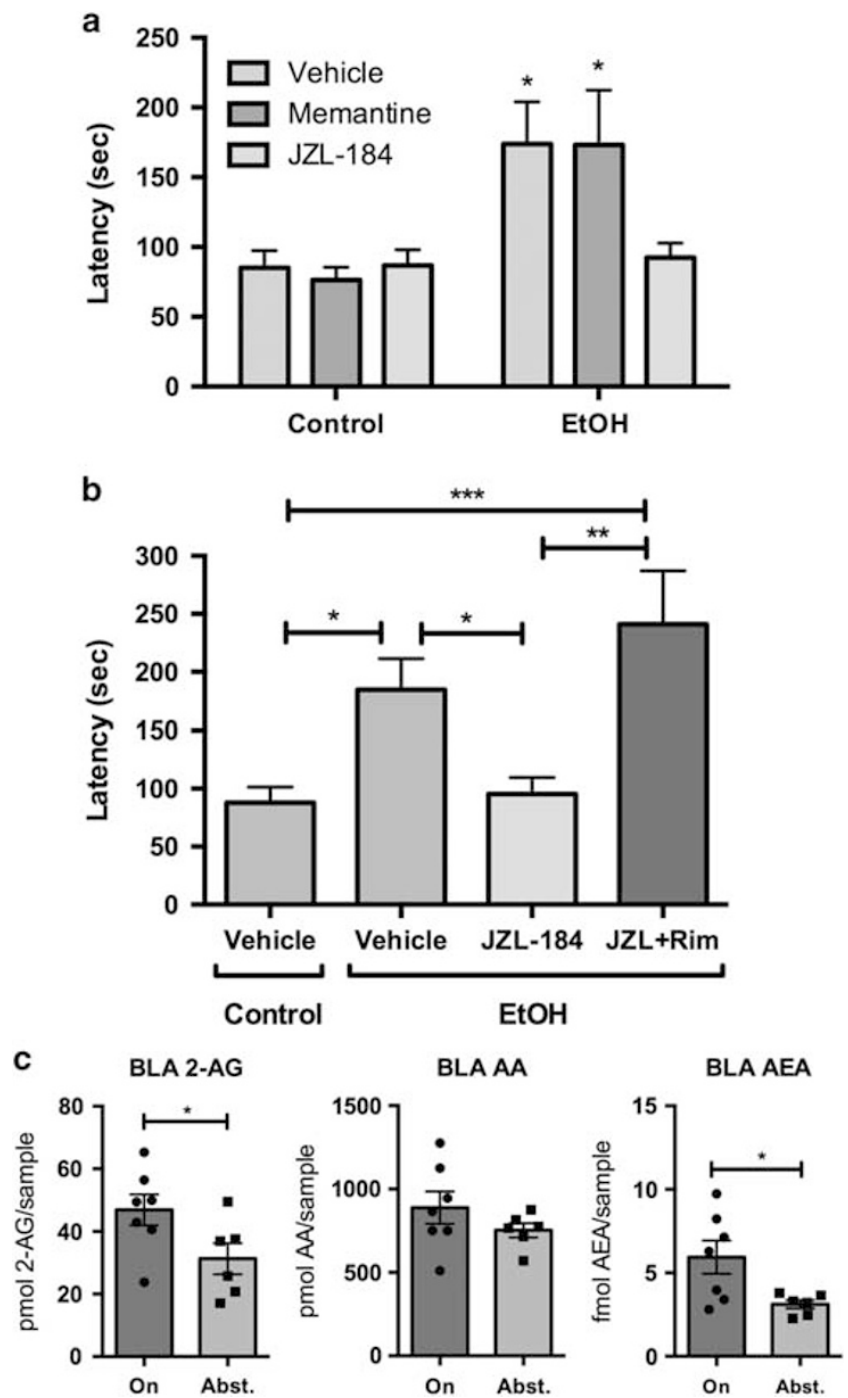

Figure 4 Endocannabinoid modulation of depression-like behavior and eCB levels during two-bottle choice paradigm and $\mathrm{EtOH}$ abstinence. (a) IZL-I 84 (8 mg/ $/ \mathrm{kg}$; $2 \mathrm{~h}$ prior to testing) completely reduced NSFT latency to baseline levels in $\mathrm{EtOH}$ abstinent mice after 15 days of abstinence, but memantine (20 mg/ $/ \mathrm{kg} ; 30$ min prior to testing) had no effect on depressionlike behavior. (b) Rimonabant (I mg/ $/ \mathrm{kg}$; $2 \mathrm{~h}$ prior to testing) blocked the effect of JZL- 184 in EtOH mice 15 days after $\mathrm{EtOH}$ removal. All drugs were administered i.p. In panel (a), groups were compared with Control-Vehicle for statistics. Groups were compared with every other group in panel (b). (c) Levels of 2-AG, AA, and AEA in the BLA after 42 days of drinking (On) or after 15 days of $\mathrm{EtOH}$ abstinence (Abst.) Data are represented as mean \pm SEM. $* P<0.05$; $* * P<0.01$; **** $P<0.00$ I. A full color version of this figure is available at the Neuropsychopharmacology journal online.

amygdala (BLA), central nucleus of the amygdala (CeA), ventral striatum, and bed nucleus of the stria terminalis (BNST). Punches were taken from mice on day 42 of EtOH drinking ( $N=6-7 ; 2-3$ mice/sample) or after 15 days of EtOH abstinence ( $N=5-6 ; 3$ mice/sample). In the BLA, both 2-AG $(P=0.049)$ and AEA $(P=0.027)$ were higher in mice drinking $\mathrm{EtOH}$ than mice in $\mathrm{EtOH}$ abstinence, while AA levels were unchanged between groups (Figure 4c). No differences in eCB levels were observed in the CeA, ventral striatum, or BNST (Supplementary Figure S1). 



Figure 5 Assessment of factors governing EtOH consumption and depressive responses. (a) Timeline of EtOH Ramp drinking paradigm. EtOH is gradually introduced and no sucrose is used. (b) Comparison of sucrose fade EtOH (EtOH (Sucr), N= 85) and EtOH Ramp $(\mathrm{N}=28)$. (c-e) Preference, consumption, and dosage of a $3 \% \mathrm{EtOH}$ solution over 2 days in naïe (3\% (Naïve); $\mathrm{N}=9$ ) or EtOH-exposed (3\% (Exposed); $N=10)$ mice, compared with mice drinking $10 \% \mathrm{EtOH}$ at the end of two-bottle choice paradigm ( $10 \% \mathrm{EtOH} ; \mathrm{N}=10)$. (c) Preference for $3 \% \mathrm{EtOH}$ is increased in mice with previous exposure to 6 weeks of $10 \% \mathrm{EtOH}$. (d, e) Consumption of $3 \% \mathrm{EtOH}$ is putatively habit-driven. (d) The same average daily volume of EtOH solution is consumed by $10 \%$ EtOH mice and 3\% (Exposed) mice. Both groups drink a greater volume than 3\% (Naïve) mice. (e) Neither 3\% (Naïve) or 3\% (Exposed) mice drink sufficient quantities to match dosage ( $\mathrm{g} / \mathrm{kg} /$ day) of $10 \%$ EtOH mice. (f, g) The EtOH Ramp procedure induces similar depression-like behavior in the NSFT following (f) I5 and (g) 35 days of abstinence. Data are represented as mean \pm SEM. $* P<0.05$; ${ }^{*} * P<0.0$ I; $* * * *<0.00$ I; $* * * * * P<0.000$ I.

Drinking Induction is not Dependent on Sucrose Fade, and Drinking Shifts to Habit-Based Consumption After 6 Weeks of EtOH Exposure

Because sucrose engages reward circuitry, some behaviors observed may be confounded as only EtOH-exposed animals were given sucrose. To address this, we utilized an EtOH ramp $(N=28)$ in lieu of sucrose fade (EtOH (Sucr); $N=85$; Figure 5a). Repeated-measures two-way ANOVA of preference utilizing EtOH (Sucr) vs EtOH Ramp (Figure 5b) revealed a significant main effect of time $(\mathrm{F}(5,555)=7.894$, $P<0.0001)$ and significant interaction $(\mathrm{F}(5,555)=35.41$; $P<0.0001)$ but no main effect of EtOH administration method $(\mathrm{F}(1,111)=0.009 ; \quad P=0.9264)$. Post-hoc analysis revealed significant differences between groups on Week 1 $(P<0.0001)$, Week $3(P<0.05)$, and Week $4(P<0.001)$.

We postulated that previous exposure to the $\mathrm{EtOH}$ paradigm might increase habit-based EtOH consumption. A shift from goal-directed to habit-based consumption is thought to characterize alcohol intake in humans with AUDs (Edwards and Koob, 2013; Everitt and Robbins, 2005). Mice did not show innate preference for 3\% EtOH (Figure 5c). We hypothesized that mice previously exposed to $10 \% \mathrm{EtOH}$ would have increased preference for $3 \% \mathrm{EtOH}$. We replaced $10 \% \mathrm{EtOH}$ with 3\% EtOH (and reversed bottle locations to avoid location preference) in mice after 42 days of $\mathrm{EtOH}$ 
access. Mice with previous EtOH exposure $(N=10)$ had significantly increased preference for $3 \% \mathrm{EtOH}$ over the naïve mice $(N=9$; Figure 5 c; $P=0.047)$. We also examined both the average amount of EtOH solution consumed (Figure $5 \mathrm{~d}$ ) and the average $\mathrm{g} / \mathrm{kg} / \mathrm{day} \mathrm{EtOH}$ (Figure $5 \mathrm{e}$ ) in three groups: mice during the final week of $10 \%$ $\mathrm{EtOH}$ exposure (10\% EtOH; $N=10)$, naïve mice given 3\% $\mathrm{EtOH}$ (3\% (Naïve); $N=9$ ), or mice with previous $10 \% \mathrm{EtOH}$ exposure given 3\% EtOH (3\% (Exposed); $N=10$ ). We hypothesized that habit-driven consumption would manifest in two ways: first, similar volumes of both 10 and $3 \% \mathrm{EtOH}$ solution would be consumed. Second, we expected 3\% (Exposed) mice would not drink sufficient quantities of EtOH to match dosage $(\mathrm{g} / \mathrm{kg} /$ day) of $10 \% \mathrm{EtOH}$ mice. One-way ANOVA of consumption (Figure 5d) revealed a significant main effect of treatment $(\mathrm{F}(2,26)=4.225$; $P=0.026$ ). 3\% (Exposed) mice drank a similar volume of EtOH solution as 10\% EtOH mice, and the 3\% (Naïve) group drank less than either other group $(P<0.05)$ using Fisher's LSD post-hoc analysis. One-way ANOVA revealed a significant main effect of treatment on $\mathrm{g} / \mathrm{kg} / \mathrm{day} \mathrm{EtOH}$ (Figure 5e; $\mathrm{F}(2,26)=130.8 ; P<0.0001)$. g/kg/day EtOH was significantly higher in the $10 \% \mathrm{EtOH}$ group compared with either 3\% EtOH group $(P<0.0001$ for both groups) using Fisher's LSD post-hoc analysis. These data indicate that consumption of 3\% EtOH following 6-week exposure to $10 \%$ $\mathrm{EtOH}$ is possibly habit-driven.

\section{Affective Disturbances Following EtOH Forced Abstinence are not Dependent on Sucrose Fade}

$\mathrm{EtOH}$ ramp procedure produced high levels of EtOH preference similar to the sucrose fade, so we hypothesized that similar behavior may be induced. As in Figure 2d, we tested for increased latency in the NSFT at both 15 (Figure 5f) and 35 (Figure 5g) days following EtOH removal in three groups: control $(N=10)$, EtOH with sucrose fade $(\mathrm{EtOH}$ (Sucr); $N=23)$, and EtOH Ramp $(N=9)$. After 15 or 35 days of forced abstinence, one-way ANOVAs revealed a significant difference between groups ( 15 days: $\mathrm{F}(2,39)=10.32, P<0.001$; 35 days: $\mathrm{F}(2,39)=6.415, P=0.004)$, and post-hoc analyses using Dunnett's multiple comparison tests showed both EtOH (Sucr) and EtOH Ramp had significantly higher NSFT latencies than control mice ( 15 days: $P<0.001$ for both groups; 35 days: $P<0.05$ for $\mathrm{EtOH}$ (Sucr) and $P<0.01$ for EtOH Ramp).

\section{DISCUSSION}

In this study, we replicated and extended previous findings that forced abstinence from EtOH drinking produces longlasting, reversible affective disturbances in mice. A continuous 6-week two-bottle choice $\mathrm{EtOH}$ drinking paradigm induced high preference for $10 \% \mathrm{EtOH}$ over water in singly housed female mice. BECs after 42 days of $10 \% \mathrm{EtOH}$ access were relatively low; however, continuous access to EtOH likely limits our ability to observe peak BECs across all animals at any given time. We replicated earlier findings (Pang et al, 2013) that subsequent forced abstinence resulted in depression-like behavior and further demonstrated that depression-like behavior requires protracted abstinence and affective disturbances are long-lasting. Both ketamine and JZL-184 reversed affective disturbances in the NSFT to control levels via two disparate pharmacological strategies. eCB levels differed in the BLA of mice currently drinking $\mathrm{EtOH} v s$ mice in EtOH abstinence. Finally, we provided evidence that this drinking paradigm induces a shift to habitbased consumption of EtOH.

Increased FST immobility is observed after 18 days-but not 1 day-of forced abstinence from EtOH. This is consistent with previous studies (Stevenson et al, 2009) and may indicate priming of depression-like behaviors during $\mathrm{EtOH}$ administration that require an abstinence incubation period to manifest. In contrast, a recent study utilizing the drinking in the dark (DID) paradigm demonstrated depression-like behavior 1-2 days following EtOH withdrawal (Lee et al, 2015). We believe our study may have uncovered an interesting distinction between our paradigm and DID. Because DID is a limited access paradigm, each daily drinking session is followed by an abstinence period. These repeated short withdrawals-not present in the current paradigm-could induce development of depression-like behavior during the course of the DID regimen. Thus, although these two paradigms model a similar component of alcohol withdrawal (depression), subtle discriminating characteristics of DID and continuous two-bottle choice may lead to a more elegant understanding of the development of depression-like behavior during abstinence.

We observe significant effects of $\mathrm{EtOH}$ abstinence in the FST and the NSFT, but not in the EPM. Although the NSFT is often thought to relay alterations in anxiety-like behavior, it has also been utilized as a measure of depression-like behavior. Given the outcomes we have observed with distinct tasks in this study, combined with the results from previous studies (Li et al, 2011; Pang et al, 2013; Santarelli et al, 2003), the total data set are most consistent with a depressive behavioral state.

Affective disturbances following $\mathrm{EtOH}$ forced abstinence are long-lasting, with increased NSFT latencies 35 days following EtOH removal. This timing agrees with substantial previous literature demonstrating incubation of drug craving during abstinence in rodents for a number of drugs of abuse (Pickens et al, 2011), including ethanol (Bienkowski et al, 2004). The protracted depression-like behavior outlined here may underlie some of the negative reinforcement thought to drive relapse to alcohol-seeking in abstinent individuals with a history of AUD (Gilpin and Koob, 2008).

Although depression is highly comorbid with alcohol use, specific investigations of drugs to treat individuals for these disorders in tandem have been woefully lacking. Typical clinical strategy regarding comorbid patients has been to treat one disorder prior to treating the other; however, as each of these disorders tend to worsen symptoms of the other, treatments for both disorders at once are needed (Pettinati et al, 2013). NMDARs represent potential targets for treating depression, as low doses of the NMDAR antagonist ketamine reduce symptoms of MDD (Berman et al, 2000) and treatment-resistant depression (Zarate et al, 2006a). Ketamine also reduces depression-like behavior in rodents (Autry et al, 2011; Li et al, 2011; Louderback et al, 2013). Interestingly, family history of alcohol use predicts greater efficacy (Phelps et al, 2009) and longer-lasting relief of depression symptoms with ketamine (Niciu et al, 2014). 
We hypothesized that ketamine would be particularly effective in reversing depression-like behavior following EtOH abstinence. Indeed, ketamine reduced NSFT latency to baseline levels.

We examined another NMDAR antagonist, memantine, in reducing depression-like behaviors. Because ketamine produces dissociative symptoms (Berman et al, 2000) and has abuse potential, similar drugs with fewer side effects are needed for the treatment of depression. Memantine has fewer reported side effects than ketamine (Parsons et al, 1999). We found that memantine at a relatively high dosage $(20 \mathrm{mg} / \mathrm{kg})$ did not reduce depression-like behavior. This is in line with previous data showing that ketamine, but not memantine, is capable of reversing depression-like behavior in mice (Gideons et al, 2014), likely because these two ligands differentially affect the NMDAR (Emnett et al, 2013; Gilling et al, 2009).

One major caveat is that NMDAR antagonists can substitute for ethanol in discriminative stimulus tasks (Kostowski and Bienkowski, 1999; Shelton, 2004). Additionally, ketamine induces alcohol intoxication-like subjective effects in humans (Dickerson et al, 2010; Krystal et al, 1998). Therefore, future studies investigating specific actions of ketamine in reducing affective behavior following $\mathrm{EtOH}$ abstinence will be invaluable in identifying therapeutic compounds lacking ketamine's abuse potential. Our laboratory and others have demonstrated that Ro25-6981, a selective antagonist of the NMDAR GluN2B subunit, mimics the antidepressant effects of ketamine (Li et al, 2011; Louderback et al, 2013). Although we did not examine subunit specificity of depression-like behavior here, future studies will aim to determine mechanistic actions of NMDAR antagonism in reducing this behavior.

Increasing levels of 2-AG through MAG lipase inhibition by JZL-184 reduces stress-induced affective disturbances (Fowler, 2015; Morena et al, 2015; Sumislawski et al, 2011). Additionally, unlike ketamine, cannabinoids and ethanol do not share discriminative stimulus profiles in rodents (Jarbe et al, 2010; McMahon et al, 2008). We sought to determine whether JZL-184 could reduce EtOH abstinence-induced depression-like behavior. Indeed, JZL-184, similar to ketamine, reversed affective disturbances in the NSFT. Additionally, co-administration of the CB1 receptor antagonist rimonabant with JZL-184 completely blocked this effect.

Modulation of the eCB system profoundly affected the affective disturbance in mice following EtOH removal, so we wondered whether the brain eCB levels differed between mice exposed to $\mathrm{EtOH}$ and mice 15 days following $\mathrm{EtOH}$ removal. We found that $2-\mathrm{AG}$ and $\mathrm{AEA}$ were reduced in the BLA during abstinence compared with current EtOH drinking. Because we only examined eCB levels in these two conditions, a caveat is that we could not determine which of these conditions produces aberrant eCB levels when compared with mice naïve to $\mathrm{EtOH}$. Acute stress reduces amygdalar AEA levels (Hill et al, 2009), and conversely, enhanced $\mathrm{eCB}$ tone reduces the stress response (Patel et al, 2004). However, chronic stress has been demonstrated to increase eCB levels in mice (Patel et al, 2009). Further investigations are crucial to determine specific contributions of eCBs to both EtOH consumption and abstinence-related behaviors using this paradigm. These findings may indicate cannabinoids as potential therapeutic targets in alcoholism and depression comorbidity.

We were initially concerned with the use of sucrose in this paradigm, as hedonic circuitry altered in a depressed-like state would certainly be engaged by sucrose. However, we found that an EtOH Ramp procedure induced both high preference drinking and similar phenotypes in the NSFT.

To assess potential habit-driven consumption following exposure to our paradigm, we further examined preference for 3\% EtOH. Mice did not prefer 3\% EtOH over water unless they had previous exposure to $10 \%$ EtOH. Mice with previous $\mathrm{EtOH}$ exposure drank the same volume of $3 \%$ $\mathrm{EtOH}$ solution as they had $10 \% \mathrm{EtOH}$ solution and did not increase consumption to sufficiently match dosage (g/kg/day) of $10 \% \mathrm{EtOH}$, lending evidence toward habitbased consumption. Typically, habit $v s$ goal-directed consumption is assessed following devaluation of the rewarding stimulus (Colwill and Rescorla, 1990). Animals will decrease effort to acquire a devalued reward if consumption is goaldirected, but habit-driven consumption proves inflexible to devaluation. Here, the $3 \% \mathrm{EtOH}$ solution could be thought to represent an innately devalued stimulus, as it does not induce preference in naïve mice. $3 \% \mathrm{EtOH}$ becomes rewarding only in mice that have acquired preference for $10 \% \mathrm{EtOH}$. Although it is tempting to interpret these findings as a shift to habit-driven consumption of $\mathrm{EtOH}$, similar to humans with AUDs (Everitt and Robbins, 2005), future studies will be necessary to fully parse out motivation in $\mathrm{EtOH}$ consumption.

Here we have shown that depression-like behavior following a two-bottle choice $10 \% \mathrm{EtOH}$ paradigm requires protracted abstinence and the affective disturbance is long-lasting. Latency in the NSFT is reduced to baseline levels with ketamine but not with memantine. Similarly, JZL-184 reduced latency to baseline levels, and this effect was blocked with co-administration of rimonabant. 2-AG and AEA levels in the BLA were higher in mice currently drinking EtOH compared with mice after 15 days of EtOH abstinence. This paradigm increased putative habit-driven consumption of a $3 \% \mathrm{EtOH}$ solution. Future studies will aim to uncover alterations in circuit-level plasticity induced by both exposure to and abstinence from $\mathrm{EtOH}$.

\section{FUNDING AND DISCLOSURE}

NIH grant support for this work was provided by F31 AA021623 (to KMH), R01 AA019455, R21 MH103950, and funding from NARSAD. SP has an active collaborative research contract with Lundbeck Pharmaceuticals. All the other authors declare no conflict of interest.

\section{REFERENCES}

Alen F, Orio L, Gorriti MA, de Heras RG, Ramirez-Lopez MT, Pozo MA et al (2013). Increased alcohol consumption in rats after subchronic antidepressant treatment. Int J Neuropsychopharmacol 16: $1809-1818$.

Autry AE, Adachi M, Nosyreva E, Na ES, Los MF, Cheng PF et al (2011). NMDA receptor blockade at rest triggers rapid behavioural antidepressant responses. Nature 475: 91-95. 
Berman RM, Cappiello A, Anand A, Oren DA, Heninger GR, Charney DS et al (2000). Antidepressant effects of ketamine in depressed patients. Biol Psychiatry 47: 351-354.

Bienkowski P, Rogowski A, Korkosz A, Mierzejewski P, Radwanska K, Kaczmarek L et al (2004). Time-dependent changes in alcoholseeking behaviour during abstinence. Eur Neuropsychopharmacol 14: 355-360.

Bodnoff SR, Suranyi-Cadotte B, Aitken DH, Quirion R, Meaney MJ (1988). The effects of chronic antidepressant treatment in an animal model of anxiety. Psychopharmacology (Berl) 95: 298-302.

Colwill RM, Rescorla RA (1990). Effect of reinforcer devaluation on discriminative control of instrumental behavior. J Exp Psychol Anim Behav Process 16: 40-47.

Daut RA, Busch EF, Ihne J, Fisher D, Mishina M, Grant SG et al (2015). Tolerance to ethanol intoxication after chronic ethanol: role of GluN2A and PSD-95. Addict Biol 20: 259-262.

Dickerson D, Pittman B, Ralevski E, Perrino A, Limoncelli D, Edgecombe $J$ et al (2010). Ethanol-like effects of thiopental and ketamine in healthy humans. J Psychopharmacol 24: 203-211.

Dulawa SC, Hen R (2005). Recent advances in animal models of chronic antidepressant effects: the novelty-induced hypophagia test. Neurosci Biobehav Rev 29: 771-783.

Dulawa SC, Holick KA, Gundersen B, Hen R (2004). Effects of chronic fluoxetine in animal models of anxiety and depression. Neuropsychopharmacology 29: 1321-1330.

Edwards S, Koob GF (2013). Escalation of drug self-administration as a hallmark of persistent addiction liability. Behav Pharmacol 24: $356-362$

Emnett CM, Eisenman LN, Taylor AM, Izumi Y, Zorumski CF, Mennerick S (2013). Indistinguishable synaptic pharmacodynamics of the N-methyl-D-aspartate receptor channel blockers memantine and ketamine. Mol Pharmacol 84: 935-947.

Everitt BJ, Robbins TW (2005). Neural systems of reinforcement for drug addiction: from actions to habits to compulsion. Nat Neurosci 8: 1481-1489.

Fowler CJ (2015). The potential of inhibitors of endocannabinoid metabolism as anxiolytic and antidepressive drugs-a practical view. Eur Neuropsychopharmacol 25: 749-762.

Gamble-George JC, Conger JR, Hartley ND, Gupta P, Sumislawski JJ, Patel S (2013). Dissociable effects of CB1 receptor blockade on anxiety-like and consummatory behaviors in the novelty-induced hypophagia test in mice. Psychopharmacology (Berl) 228: 401-409.

Gartlehner G, Thaler K, Hill S, Hansen RA (2012). How should primary care doctors select which antidepressants to administer? Curr Psychiatry Rep 14: 360-369.

Gideons ES, Kavalali ET, Monteggia LM (2014). Mechanisms underlying differential effectiveness of memantine and ketamine in rapid antidepressant responses. Proc Natl Acad Sci USA 111: 8649-8654.

Gilling KE, Jatzke C, Hechenberger M, Parsons CG (2009). Potency, voltage-dependency, agonist concentration-dependency, blocking kinetics and partial untrapping of the uncompetitive N-methylD-aspartate (NMDA) channel blocker memantine at human NMDA (GluN1/GluN2A) receptors. Neuropharmacology 56: 866-875.

Gilpin NW, Koob GF (2008). Neurobiology of alcohol dependence: focus on motivational mechanisms. Alcohol Res Health 31: 185-195.

Grant BF, Goldstein RB, Saha TD, Chou SP, Jung J, Zhang H et al (2015). Epidemiology of DSM-5 alcohol use disorder: results from the National Epidemiologic Survey on Alcohol and Related Conditions III. JAMA Psychiatry 72: 757-766.

Grigoriadis S, Robinson GE (2007). Gender issues in depression. Ann Clin Psychiatry 19: 247-255.

Heilig M, Egli M, Crabbe JC, Becker HC (2010). Acute withdrawal, protracted abstinence and negative affect in alcoholism: are they linked? Addict Biol 15: 169-184.

Hill MN, McLaughlin RJ, Morrish AC, Viau V, Floresco SB, Hillard CJ et al (2009). Suppression of amygdalar endocannabinoid signaling by stress contributes to activation of the hypothalamic-pituitary-adrenal axis. Neuropsychopharmacology 34: 2733-2745.

Jarbe TU, Li C, Vadivel SK, Makriyannis A (2010). Discriminative stimulus functions of methanandamide and delta(9)-THC in rats: tests with aminoalkylindoles (WIN55,212-2 and AM678) and ethanol. Psychopharmacology (Berl) 208: 87-98.

Kash TL, Baucum AJ, Conrad KL, Colbran RJ, Winder DG (2009). Alcohol exposure alters NMDAR function in the bed nucleus of the stria terminalis. Neuropsychopharmacology 34: 2420-2429.

Kliethermes CL (2005). Anxiety-like behaviors following chronic ethanol exposure. Neurosci Biobehav Rev 28: 837-850.

Kostowski W, Bienkowski P (1999). Discriminative stimulus effects of ethanol: neuropharmacological characterization. Alcohol 17: 63-80.

Krystal JH, Petrakis IL, Webb E, Cooney NL, Karper LP, Namanworth S et al (1998). Dose-related ethanol-like effects of the NMDA antagonist, ketamine, in recently detoxified alcoholics. Arch Gen Psychiatry 55: 354-360.

Lee KM, Coehlo M, McGregor HA, Waltermire RS, Szumlinski KK (2015). Binge alcohol drinking elicits persistent negative affect in mice. Behav Brain Res 291: 385-398.

Li N, Liu RJ, Dwyer JM, Banasr M, Lee B, Son H et al (2011). Glutamate N-methyl-D-aspartate receptor antagonists rapidly reverse behavioral and synaptic deficits caused by chronic stress exposure. Biol Psychiatry 69: 754-761.

Louderback KM, Wills TA, Muglia LJ, Winder DG (2013). Knockdown of BNST GluN2B-containing NMDA receptors mimics the actions of ketamine on novelty-induced hypophagia. Transl Psychiatry 3: e331.

Lovinger DM, Crabbe JC (2005). Laboratory models of alcoholism: treatment target identification and insight into mechanisms. Nat Neurosci 8: 1471-1480.

McMahon LR, Ginsburg BC, Lamb RJ (2008). Cannabinoid agonists differentially substitute for the discriminative stimulus effects of Delta(9)-tetrahydrocannabinol in C57BL/6J mice. Psychopharmacology (Berl) 198: 487-495.

Middaugh LD, Kelley BM, Bandy AL, McGroarty KK (1999). Ethanol consumption by C57BL/6 mice: influence of gender and procedural variables. Alcohol 17: 175-183.

Morena M, Patel S, Bains JS, Hill MN (2015). Neurobiological interactions between stress and the endocannabinoid system. Neuropsychopharmacology 41: 80-102.

Niciu MJ, Luckenbaugh DA, Ionescu DF, Richards EM, Vande Voort JL, Ballard ED et al (2014). Ketamine's antidepressant efficacy is extended for at least four weeks in subjects with a family history of an alcohol use disorder. Int J Neuropsychopharmacol 18: 119-139.

Pang TY, Renoir T, Du X, Lawrence AJ, Hannan AJ (2013). Depression-related behaviours displayed by female C57BL/6J mice during abstinence from chronic ethanol consumption are rescued by wheel-running. Eur J Neurosci 37: 1803-1810.

Parsons CG, Danysz W, Quack G (1999). Memantine is a clinically well tolerated N-methyl-D-aspartate (NMDA) receptor antagonist-a review of preclinical data. Neuropharmacology 38: 735-767.

Patel S, Kingsley PJ, Mackie K, Marnett LJ, Winder DG (2009). Repeated homotypic stress elevates 2-arachidonoylglycerol levels and enhances short-term endocannabinoid signaling at inhibitory synapses in basolateral amygdala. Neuropsychopharmacology 34: 2699-2709.

Patel S, Roelke CT, Rademacher DJ, Cullinan WE, Hillard CJ (2004). Endocannabinoid signaling negatively modulates stressinduced activation of the hypothalamic-pituitary-adrenal axis. Endocrinology 145: 5431-5438.

Pettinati HM, O'Brien CP, Dundon WD (2013). Current status of co-occurring mood and substance use disorders: a new therapeutic target. Am J Psychiatry 170: 23-30. 
Phelps LE, Brutsche N, Moral JR, Luckenbaugh DA, Manji HK, Zarate CA Jr (2009). Family history of alcohol dependence and initial antidepressant response to an N-methyl-D-aspartate antagonist. Biol Psychiatry 65: 181-184.

Pickens CL, Airavaara M, Theberge F, Fanous S, Hope BT, Shaham Y (2011). Neurobiology of the incubation of drug craving. Trends Neurosci 34: 411-420.

Prencipe L, Iaccheri E, Manzati C (1987). Enzymic ethanol assay: a new colorimetric method based on measurement of hydrogen peroxide. Clin Chem 33: 486-489.

Santarelli L, Saxe M, Gross C, Surget A, Battaglia F, Dulawa $S$ et al (2003). Requirement of hippocampal neurogenesis for the behavioral effects of antidepressants. Science 301: 805-809.

Shelton KL (2004). Substitution profiles of N-methyl-D-aspartate antagonists in ethanol-discriminating inbred mice. Alcohol 34: $165-175$.
Stevenson JR, Schroeder JP, Nixon K, Besheer J, Crews FT, Hodge CW (2009). Abstinence following alcohol drinking produces depression-like behavior and reduced hippocampal neurogenesis in mice. Neuropsychopharmacology 34: 1209-1222.

Sumislawski JJ, Ramikie TS, Patel S (2011). Reversible gating of endocannabinoid plasticity in the amygdala by chronic stress: a potential role for monoacylglycerol lipase inhibition in the prevention of stress-induced behavioral adaptation. Neuropsychopharmacology 36: 2750-2761.

Zarate CA Jr, Singh JB, Carlson PJ, Brutsche NE, Ameli R, Luckenbaugh DA et al (2006a). A randomized trial of an $\mathrm{N}$-methyl-D-aspartate antagonist in treatment-resistant major depression. Arch Gen Psychiatry 63: 856-864.

Zarate CA Jr, Singh JB, Quiroz JA, De Jesus G, Denicoff KK, Luckenbaugh DA et al (2006b). A double-blind, placebocontrolled study of memantine in the treatment of major depression. Am J Psychiatry 163: 153-155.

Supplementary Information accompanies the paper on the Neuropsychopharmacology website (http://www.nature.com/npp) 